\title{
SOCIAL NETWORK SIZE IN HUMANS
}

\author{
R. A. Hill \\ University of Durham \\ and \\ R. I. M. Dunbar \\ University of Liverpool
}

This paper examines social network size in contemporary Western society based on the exchange of Christmas cards. Maximum network size averaged 153.5 individuals, with a mean network size of 124.9 for those individuals explicitly contacted; these values are remarkably close to the group size of 150 predicted for humans on the basis of the size of their neocortex. Age, household type, and the relationship to the individual influence network structure, although the proportion of kin remained relatively constant at around $21 \%$. Frequency of contact between network members was primarily determined by two classes of variable: passive factors (distance, work colleague, overseas) and active factors (emotional closeness, genetic relatedness). Controlling for the influence of passive factors on contact rates allowed the hierarchical structure of human social groups to be delimited. These findings suggest that there may be cognitive constraints on network size.

KEY WORDS: Frequency of contact; Group size; Humans; Neocortex size; Social networks

Received March 22, 2002; accepted July 19, 2002; revised version received October 30, 2002.

Address all correspondence to Evolutionary Anthropology Research Group, Department of Anthropology, University of Durham, 43 Old Elvet, Durham DH1 3HN, U.K. Email: r.a.hill@durham.ac.uk

Copyright 2003 by Walter de Gruyter, Inc., New York

Human Nature, Vol. 14, No. 1, pp. 53-72.

$1045-6767 / 03 / \$ 1.00+.10$ 
Analyses of human social networks have a long history in both the sociological and anthropological literature (Milardo 1988). However, relatively few studies have attempted to investigate complete social networks in humans (McCarty et al. 1997), primarily due to the difficulty in estimating and defining an individual's "network" from the range of interactions that exist within everyday life. As a result, studies have tended to focus on determining total network size (Johnson et al. 1995; Killworth et al. 1990, 1998; McCarty et al. 2001; Pool and Kochen 1978), with relatively little attention paid to the interactions within these networks. However, depending on the definition of personal networks, and the required relationships or ties between individuals to warrant inclusion in a network, previous studies have found total networks to run from about 250 individuals (Killworth et al. 1984) to approximately 5,000 (Pool and Kochen 1978; Killworth et al. 1990). There is thus little consensus as to what constitutes a social network in humans.

In primates, social networks are more easy to define (see Kudo and Dunbar 2001) and are often delimited by the size of the social group. Furthermore, primate social relationships are generally characterized by intense social grooming (Dunbar 1991), and both primate group size (Dunbar 1992) and grooming clique size (Kudo and Dunbar 2001) are a function of relative neocortical volume. Similar relationships have been reported for carnivores (Dunbar and Bever 1998) and cetaceans (Marino 1996; Tschudin 1997). These findings suggest that there may be a cognitive constraint on the size of social networks in those species that live in intensely social groups (as opposed to simple aggregations), perhaps because the number or volume of neocortical neurons limits an organism's information processing capacity, and hence the number of social relationships that an individual can monitor simultaneously (Dunbar 1992, 1998; Barton and Dunbar 1997).

Since the size of the human neocortex is known, the relationship between group size and neocortex size in primates can be used to predict the cognitive group size for humans. Dunbar (1993) utilized this approach to predict that humans should live in social groups of approximately 150 individuals. Evidence from the ethnological literature provides some support for this, since census data from a range of tribal and more traditional societies indicate that groups of about this size are in fact a common component of human social systems (see data collated by Dunbar 1993; see also Barrett et al. 2002).

This raises the question as to whether modern, postindustrial societies also exhibit a similar pattern, with a discernible grouping of about 150 individuals embedded into the somewhat diffuse and dispersed social systems in which most of us now live. Recent approaches for estimating personal network sizes in contemporary societies have asked respondents to estimate the number of people they know in specific subpopulations of 
known size (e.g., diabetics) to generate estimates of maximum network size (McCarty et al. 2001). Such methods, while producing reliable estimates of maximum network sizes that can have a number of applied implications (e.g., Killworth et al. 1998), provide little information on which relationships are valued within networks or the way in which networks are maintained. Furthermore, they also estimate the maximum number of individuals known, rather than identifying those people an individual considers important and whose relationship they value. As a consequence, they tell us little about the way in which humans may actively maintain contact with a network of specific individuals.

In Western societies at least, the exchange of Christmas cards represents the one time of year when individuals make an effort to contact all those individuals within their social network whose relationships they value. As a consequence, this activity provides a unique insight not only into the size of individuals' social networks, but also into the way in which these networks are structured, both in terms of demographic composition and the frequencies with which individual relationships are serviced.

\section{METHODS}

A questionnaire was designed to be completed as individuals were sending out their Christmas cards. Such timing should ensure that selfreporting errors are minimized (a significant problem in previous studies: Milardo 1988), since responses did not rely upon the memory of those completing the questionnaire. In recent years, questionnaire design has been the focus of considerable discussion (Milardo, ed. 1988; McCarty et al. 1997); the main conclusion from this has been that questionnaires which take more than a few minutes to complete or are too complex in their design tend to result in loss of concentration and poor levels of completion (Dunbar and Spoors 1995). Because the information we required was both detailed and lengthy, we preferred a design in which a small number of individuals distributed questionnaires to personal acquaintances. Although this drastically reduces the number of individuals who receive questionnaires, the sense of obligation that a respondent owes to the distributor from whom he/she received the questionnaire greatly increases the return rate (proportion of all questionnaires completed and returned), especially when that questionnaire is long and complex. Only one questionnaire was completed per household, but there remains a potential for overlap between households that belong to the same extended social network. However, everyday experience suggests that even close friends in modern urban society do not share all their friends and acquaintances; moreover, there is no reason to suspect that the size of any one person's social net- 
work dictates in any way the size of anyone else's when they do not belong to the same household. To minimize possible cultural effects (e.g., Kim and McKenry 1998), all respondents were white British.

In completing the questionnaire, respondents were initially asked for their age and sex and the number and identity of individuals living in their household. Respondents were also asked to list those individuals to whom they regularly send cards but were not doing so this year because they expected to see them at Christmas. These individuals, as well as household members, were included in the analyses of network size since they are clearly integral to the respondents' social networks even though they might not be included in the Christmas card network. For each Christmas card, respondents were asked to provide a number of details about the individual (or individuals) to whom the card was being sent (see Table 1). For certain analyses, responses were recoded to produce data in a more quantifiable format. In terms of social status, the recipient household was classified as one of three categories: individual, couple, or family. Similarly, an individual's relationship to a given recipient was coded as one of four categories: relative, friend, neighbor, or work colleague. In order to account for potential differences between genetic relatives and relatives by marriage, we created two measures of relatedness; genetic relatedness (the

Table 1. Information Requested on Questionnaire To Be Listed for Each Christmas Card

\begin{tabular}{ll}
\hline Category & \multicolumn{1}{c}{ Definition } \\
\hline Distance & $\begin{array}{c}\text { Approximate distance to recipient in miles (overseas } \\
\text { individuals were listed by country-mean distance to } \\
\text { that country was later estimated for analysis) } \\
\text { Relationship of respondent to contact: relative (stating } \\
\text { degree of relatedness, e.g., brother, sister-in-law, niece), } \\
\text { welationship } \\
\text { work colleague, friend, neighbor } \\
\text { Social structure of individuals contacted: single individ- } \\
\text { ual, couple, or family (indicating structure of family, } \\
\text { e.g., husband, wife, 3 children) as well as which indi- } \\
\text { viduals within household were contacted directly (e.g., } \\
\text { wife only) } \\
\text { An estimate to the nearest month, or week if contact is } \\
\text { within last month, of when the respondent was last in } \\
\text { contact with their acquaintance, or to indicate that pre- } \\
\text { vious contact was by last Christmas card only. If a let- } \\
\text { ter or long message was included in the Christmas } \\
\text { card this was also noted. } \\
\text { A rating of how emotionally close the respondent felt to } \\
\text { the principal contact where } 10 \text { is very emotionally } \\
\text { close and 0 is not emotionally close at all }\end{array}$ \\
Emotional Closeness
\end{tabular}


coefficient of relatedness) and affinal relatedness (an index that mirrored exactly the equivalent genetic relationship-i.e., a brother-in-law is considered to have the same coefficient of relatedness as a full biological brother, namely 0.5 ). Although it is possible that not all affinal relatives were identified as such on the questionnaires (few respondents, for example, distinguished between biological and affinal nephews and nieces), such that they were taken to be genetic kin, the two categories at least allow a preliminary exploration of the extent to which distinctions are made between biological and social relatives in managing social networks.

Because respondents were completing questionnaires on behalf of a household (most Christmas cards are typically sent from all members of the household, or at least the adults), we make no attempt to determine the importance of gender in determining network size. Although sex differences in network size have been reported in previous studies (Dickens and Perlman 1981; for empathy groups and support cliques only: Dunbar and Spoors 1995), the sampling design we have used makes it inappropriate to explore this issue in the present case.

All continuous variables were tested for normality, and where they were found to deviate significantly from the normal distribution (Kolmogorov Smirnov, $p<0.05)$, the data were log-transformed for certain analyses. All tests are two-tailed.

\section{RESULTS}

Forty-three questionnaires were returned, between them involving a total of 2,984 Christmas cards. The number of individuals contacted via each card ranged from 1 to 9 . The mean number of Christmas cards sent was 68.19 (range 11-149). Since many cards were sent to couples and families, this results in a mean network size of 153.5 ( \pm 84.5) (Figure 1). However, if we consider only those individuals whom respondents stated they actively contacted (as opposed to everyone actually residing in the household to which the card was sent), then mean network size is 124.9 ( \pm 68.0$)$ for the 22 questionnaires for which this distinction was made.

There is a near-significant quadratic relationship between maximum network size and age of the respondent (Figure 2: $r^{2}=0.132, F_{2,40}=3.04$, $p=0.059$ ). While there is considerable variation in maximum network size throughout the entire age range, it is clear that large network sizes are not especially characteristic of either young or old individuals. These results remain broadly similar if the number of individuals actually contacted is considered.

The recipients of cards can be differentiated by whether they live alone, as a couple, or as a family. Significant differences exist in the proportion 


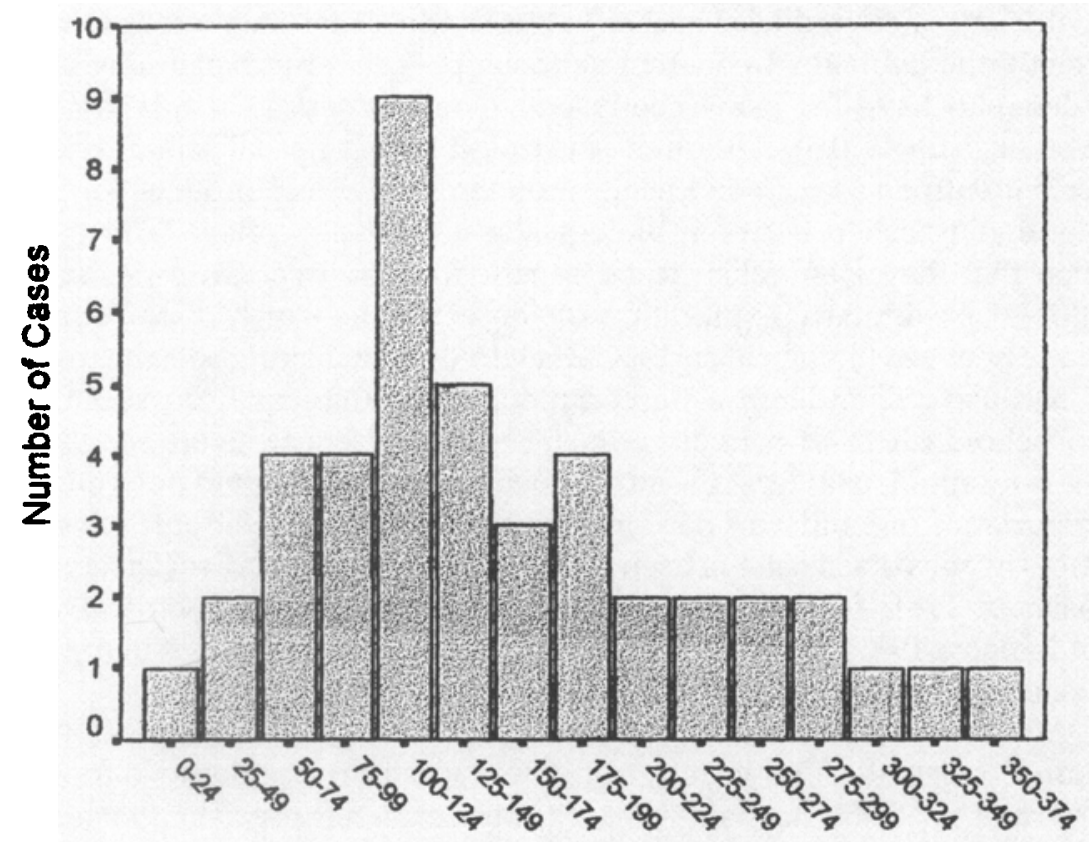

\section{Maximum Network Size}

Figure 1. Frequency distribution of total number of individuals in respondents' social networks.

of the maximum network that is made up of these three categories of recipients, and these compositions are also influenced by age (Figure 3: $r^{2}$ $=0.559 ; F_{14,129}=11.00, p<0.001$; household type factor: $F_{2,129}=30.4, p<$ 0.001 ; household by age interaction: $F_{8,129}=7.6, p<0.001$ ). Almost identical relationships are observed if the analysis is conducted for those network members actually contacted or by the number of Christmas cards sent.

Previous studies have often sought to examine network composition in terms of kinship and other relationship categories. Within this sample, there are significant differences in the proportion of maximum network size that is made up by five main relationship types (genetic relative, affinal relative, friend, neighbor, and work colleague), although these proportions are not influenced by age (Figure $4: r^{2}=0.857 ; F_{24,215}=57.45, p<$ 0.001 ; relationship type factor: $F_{4,215}=229.6, p<0.001$; relationship by age interaction: $F_{16,215}=1.10, p>0.30$ ). The mean proportion of each relationship type within the typical maximum Christmas card network is 0.21 for genetic relatives, 0.04 for non-genetic relatives (thus 0.25 for all relatives combined), 0.63 for friends, 0.04 for neighbors, and 0.08 for work col- 


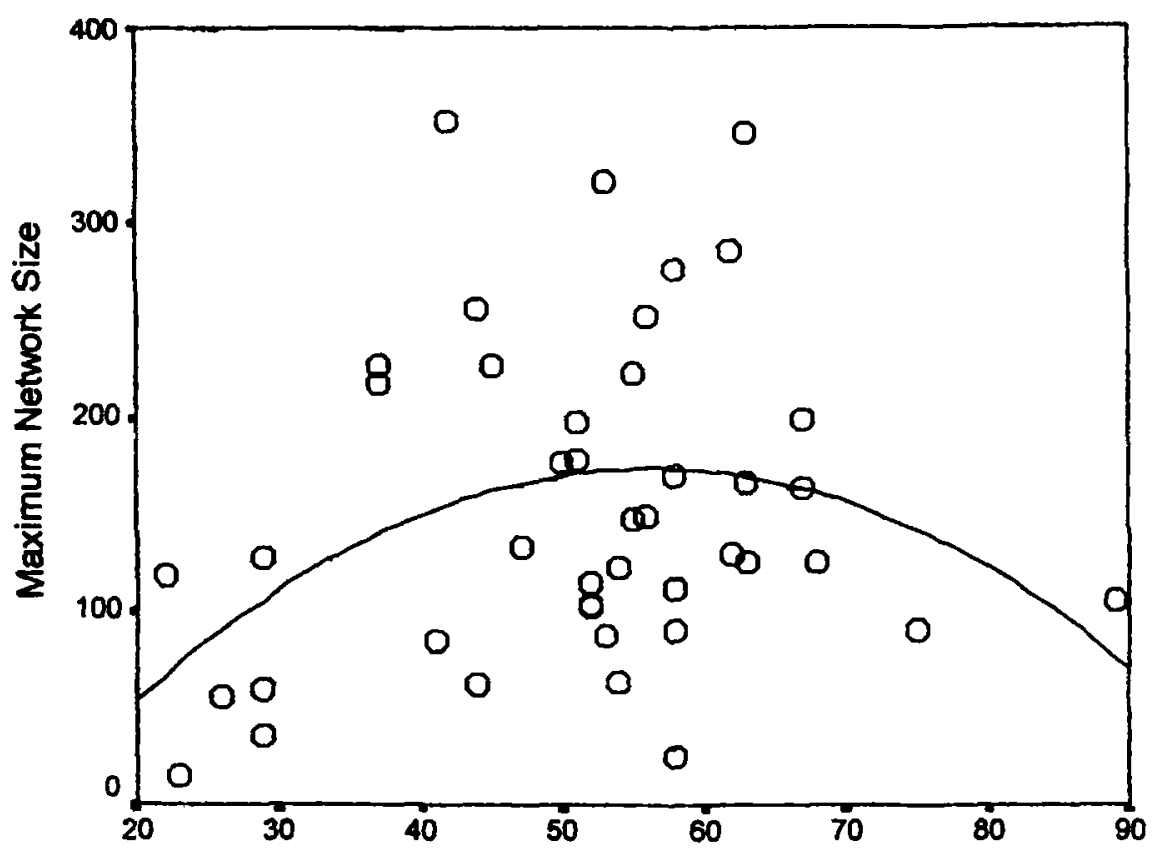

Age of Respondant

Figure 2. Relationship between maximum network size and age.

leagues. Again the results are virtually identical if the analysis is repeated by number of Christmas cards sent or only for those network members contacted directly.

Stepwise least-squares regression was used to determine the factors that best explain the patterns of contact within an individual's network. The best-fitting model, given in Table 2, incorporates seven variables in the final model $\left(r^{2}=0.394, F_{7,2909}=269.66, p<0.0001\right)$, with only the variable for whether an individual is a spouse/partner excluded from the list of available independent variables. Time since last contact increases as distance to the individual increases, decreases as emotional closeness increases, decreases if the individual is a work colleague, decreases if the contact is overseas, decreases as the coefficient of relatedness increases for both genetic and affinal relatives, and increases with age. The sign of the relationship for overseas contacts has changed relative to a simple bivariate correlation $(r=$ $0.192, N=2984, p<0.0001$ ), suggesting that people overseas are contacted more frequently once distance, emotional closeness, and whether the individual is a work colleague have been controlled for. 


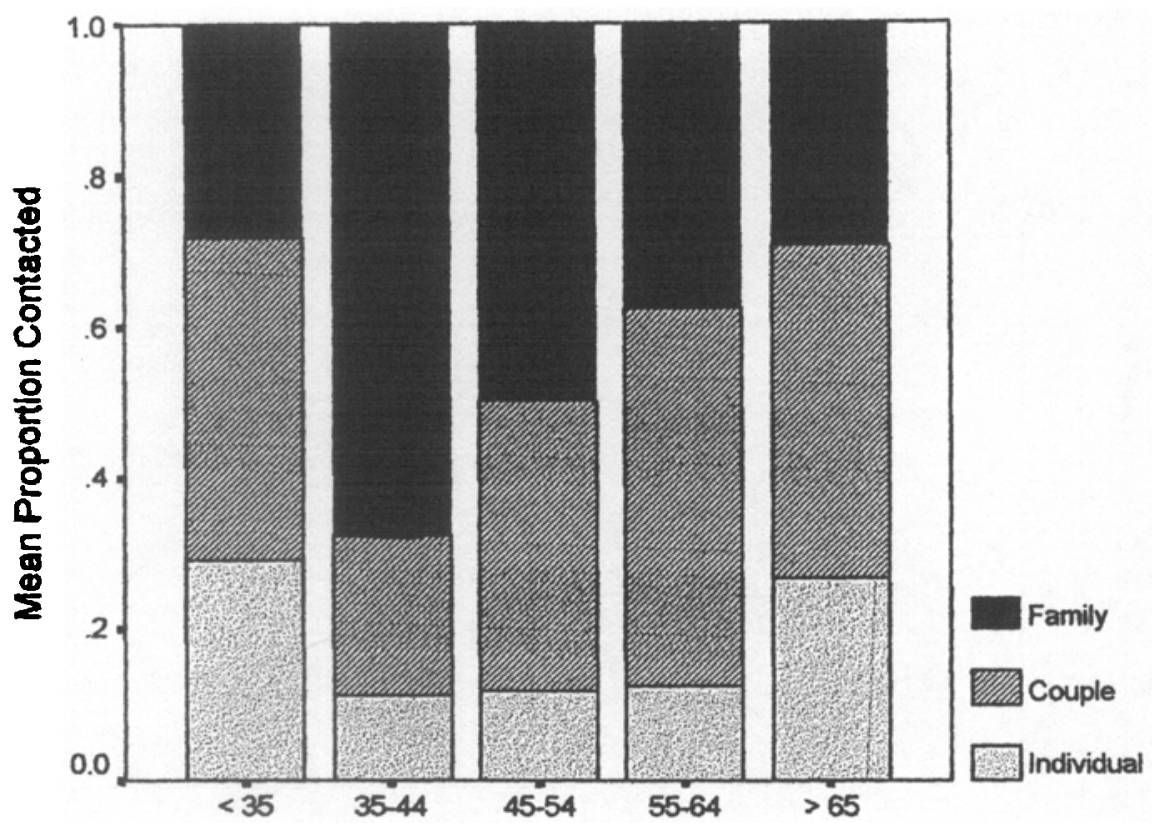

Age

Figure 3. Mean proportion of total network made up of different household types for five age categories.

In cases where recipients were contacted only once a year, respondents sometimes included a letter or extended message in their card. This practice might indicate that these recipients were held in higher regard. For this subset of the social network, distance to contact, emotional closeness, and relatedness for genetic relatives all form significant components of a logistic regression model determining whether or not a letter is included with the card (Table 3). The probability of a letter being included with a Christmas card increases with distance to contact and emotional closeness, but decreases with genetic relatedness. The coefficient of relatedness for affinal relatives does not form a significant component of this model. However, since all affinal relatives may not have been identified as such on the questionnaires (and thus classified as genetic relatives), there may still be a partial effect for affinal relatives. This is suggested by the fact that treating the coefficient of relatedness for all relatives combined as a single independent variable results in a slight improvement on the overall model $\left(r^{2}=0.192,-2 \mathrm{LL}=783.15, \mathrm{df}=3, p<0.0001\right.$; relatedness term: $r^{2}=0.014$, 


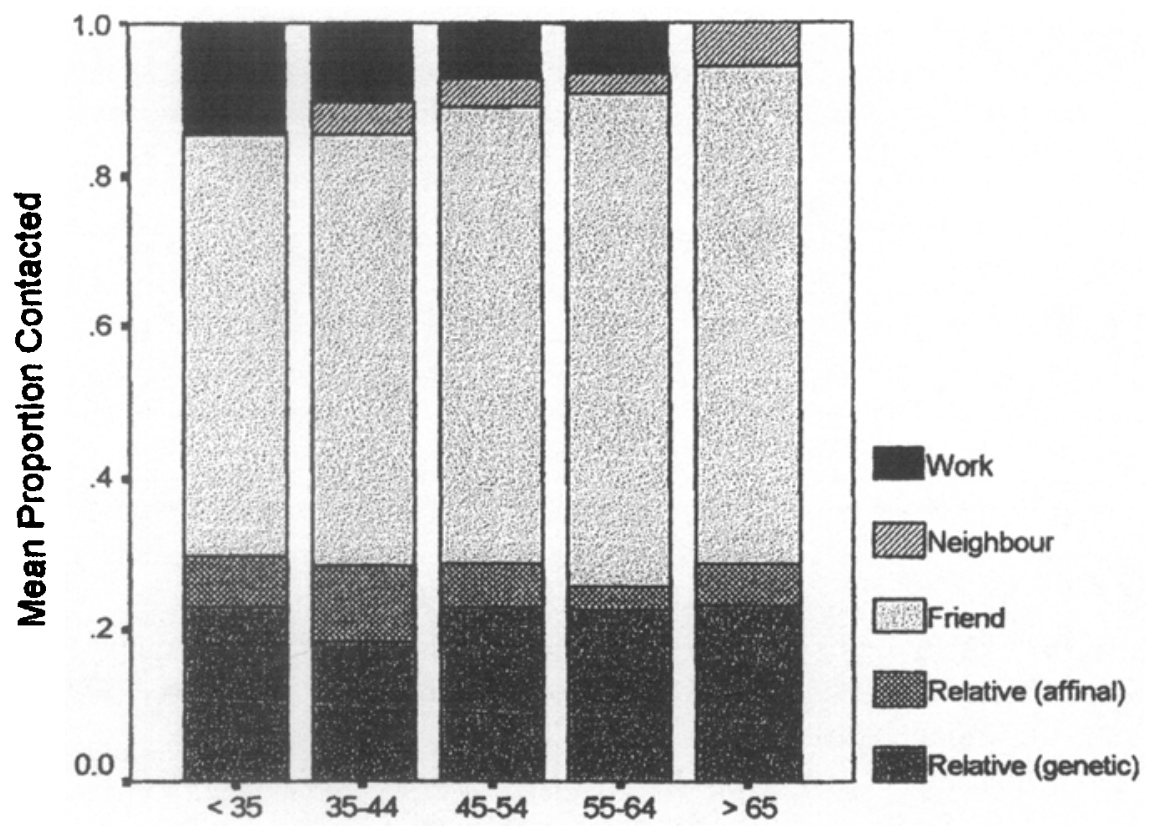

Age

Figure 4. Mean proportion of total network made up of kin, non-genetic relatives, friends, neighbors, and work colleagues for five age categories.

Table 2. Stepwise Regression Analysis of Factors Determining Time to Most Recent Contact (An independent variable not incorporated in the final model is Spouse/Partner [YES/NO].)

\begin{tabular}{|c|c|c|c|}
\hline & $r^{2}$ & $F_{7,2902}$ & $p$ \\
\hline Final Model & 0.393 & 268.855 & $<0.0001$ \\
\hline Variable & $r^{2}$ & $B$ & $p$ \\
\hline Constant & 一 & 0.292 & $<0.01$ \\
\hline Log (Distance to Contact) & 0.221 & 0.243 & $<0.0001$ \\
\hline Log (Emotional Closeness) & 0.099 & -0.610 & $<0.0001$ \\
\hline Work Colleague (YES/NO) & 0.051 & -0.385 & $<0.0001$ \\
\hline Overseas (YES/NO) & 0.012 & -0.245 & $<0.0001$ \\
\hline Log (Relatedness-Genetic) & 0.004 & -0.738 & $<0.0001$ \\
\hline Log (Relatedness-Affinal) & 0.004 & -0.922 & $<0.0001$ \\
\hline Log (Age of Respondent) & 0.002 & 0.217 & $<0.0001$ \\
\hline
\end{tabular}


Table 3. Logistic Regression Analysis of Factors Determining Whether a Letter Is Included with the Christmas Card (for those individuals in the network contacted by Christmas card only). Independent variables in initial model are those included in the linear regression analysis.

\begin{tabular}{lccccc}
\hline & $r^{2}$ & $-2 \log L$ & $\chi^{2}$ & $d f$ & $p$ \\
\cline { 2 - 6 } Final Model & 0.187 & 783.149 & 111.617 & 3 & $<0.0001$ \\
\hline Variable & $r^{2}$ & \multicolumn{1}{c}{$B$} & Wald & $d f$ & $p$ \\
\cline { 2 - 6 } Log (Distance to Contact) & 0.153 & 0.845 & 63.96 & 1 & $<0.0001$ \\
Log (Emotional Closeness) & 0.026 & 2.034 & 17.73 & 1 & $<0.0001$ \\
Log (Genetic Relatedness) & 0.008 & -6.961 & 4.75 & 1 & $<0.03$ \\
Constant & - & -4.479 & 121.80 & 1 & $<0.0001$ \\
\hline
\end{tabular}

Wald $=7.78, \mathrm{df}=1, p=0.005)$. Nevertheless, the possibility exists that the respondent may only make the effort of writing a letter if the recipient is their own genetic kin.

Recent studies have suggested that human social networks have a hierarchical structure, with frequency of contact being used to differentiate between levels within the social network (Dunbar 1993; Dunbar and Spoors 1995). However, since frequency of contact is dependent on stochastic factors it is not surprising that there is considerable variation in the reported hierarchical group size estimates (e.g., published sympathy group sizes range from 7 to 20: Dunbar and Spoors 1995; Hays and Oxley 1986; McCannell 1988; Rands 1988). The preceding analysis indicated that three "passive" factors might influence frequency of contact between network members independent of any intentional contact: distance to individual and whether the contact is a work colleague or lives overseas. If the combined influence of these factors is controlled for, we should get a clearer picture of whether social networks are differentiated hierarchically on the basis of frequency of contact.

Figure 5 displays cumulative network size against residual frequency of contact, controlling for distance and whether the contact is a work colleague or overseas. Reference lines are displayed to indicate the approximate hierarchical grouping levels identified by Dunbar (1998). Clear inflection points can be observed at 7,20 , and 35 individuals, respectively. Inspection of the pattern in Figure 5 suggests that further grouping levels might also be identified at about 70 and 100 individuals.

Figure 6 suggests that, once stochastic factors have been accounted for, emotional closeness is likely to be the key parameter underlying the frequency of contact between individuals: time since last contact declines as the level of emotional closeness increases. The apparently high contact 


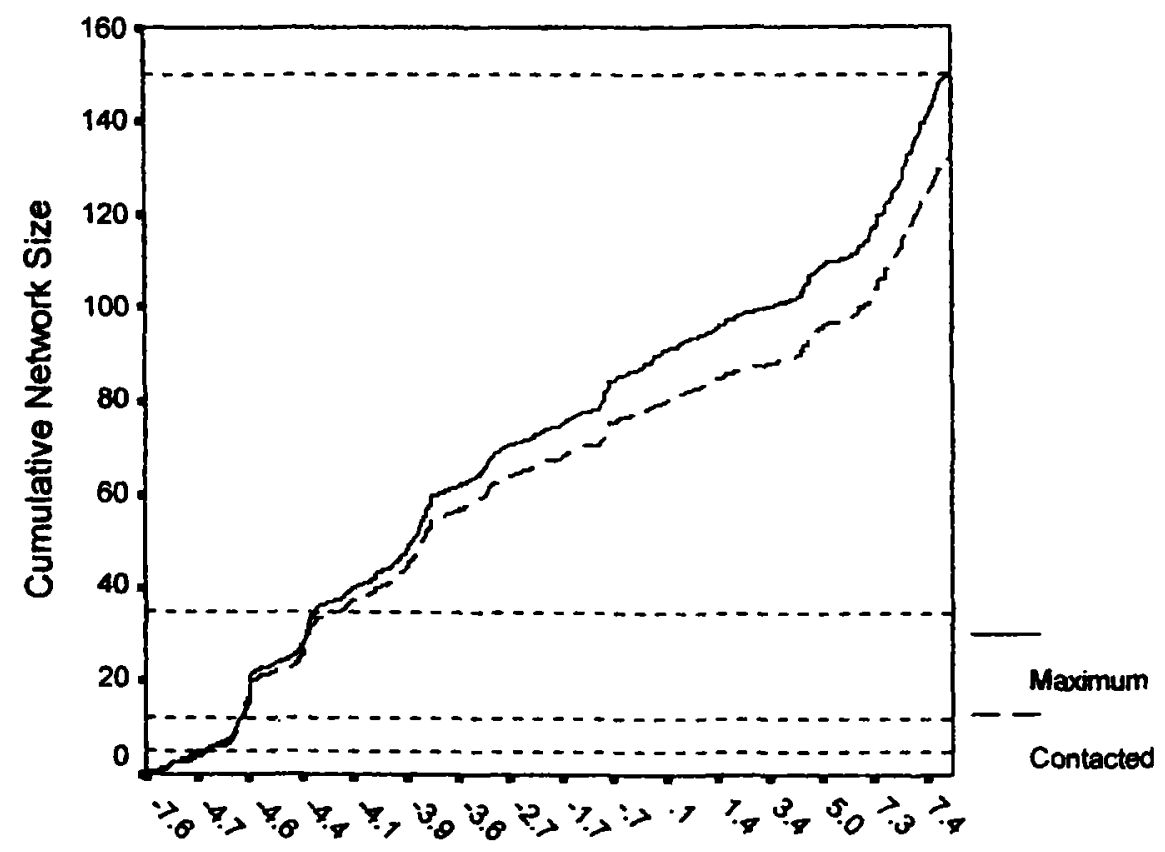

Residual Contact Frequency

Figure 5. Cumulative network size on the basis of frequency of contact, controlling for distance to contact and whether the contact is a work colleague or overseas, for maximum network reached and those actively contacted. Horizontal lines indicate approximate hierarchical grouping levels reported in the literature (Dunbar 1998: support cliques 5; sympathy groups 12; bands 35; cognitive group size $\sim 150$ ).

frequencies for individuals ranked as zero emotional closeness are almost certainly a sampling artifact. Only four questionnaires utilized the zero emotional closeness value, and two-thirds of these data were from a single questionnaire. Thus the low degree of emotional differentiation employed by this respondent, coupled with a small sample size for this emotional closeness category, may be the explanation for the apparently anomalous downturn on the left-hand side of Figure 6. Despite this, there is a clear trend for contact latency to decline as emotional closeness increases, such that those of the highest emotional closeness are invariably contacted on a weekly basis. In turn, this suggests that emotional closeness may be the key parameter underlying the hierarchical differentiation of social networks. 


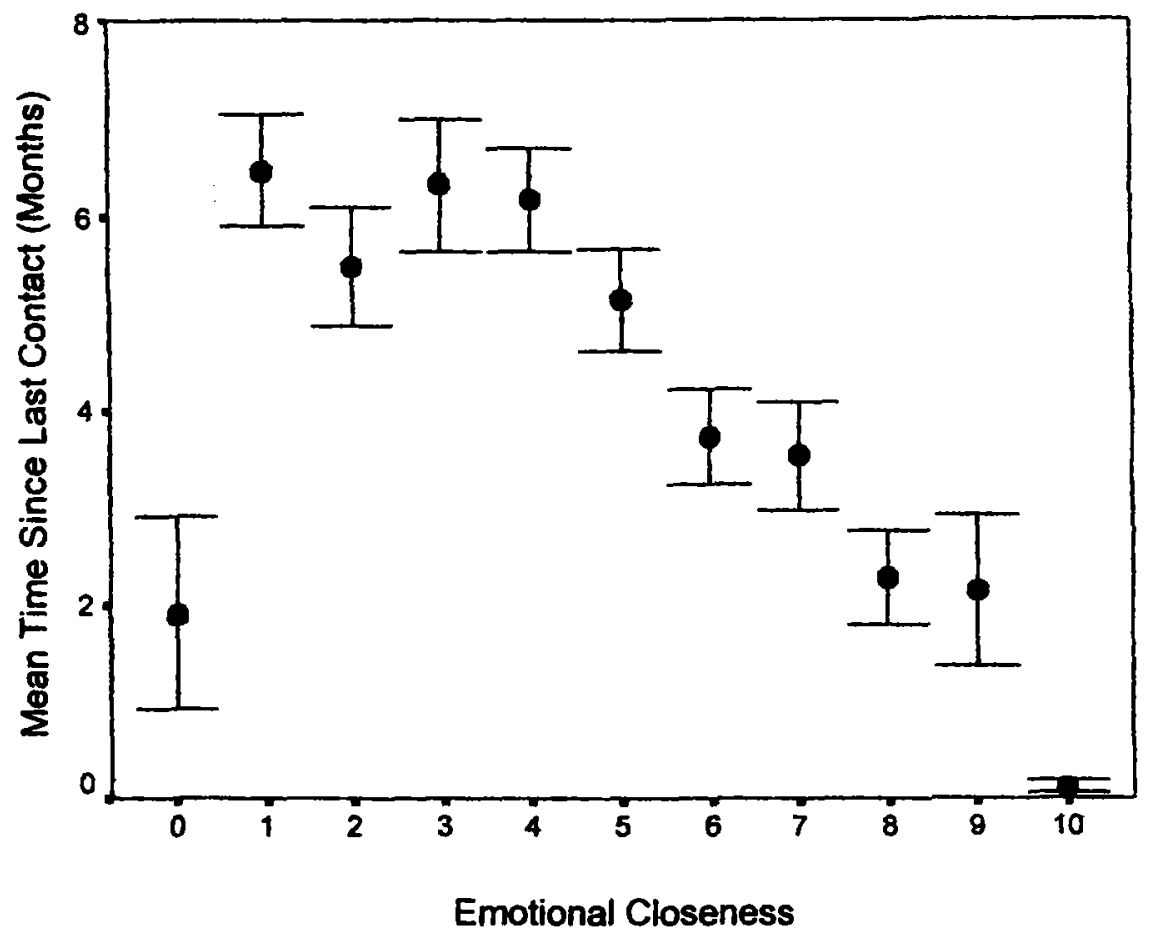

Figure 6. Mean (and standard error) number of months since last contact between individuals based on their degree of emotional closeness.

\section{DISCUSSION}

In contemporary Western societies, we regularly interact with a wide array of other individuals: social networks of up to 5000 individuals have, for example, been reported (Pool and Kochen 1978; Killworth et al. 1990). However, many of the individuals we meet in this way do not form a part of our intimate social network, and we have no formal relationships with them. In contrast, the relationship between neocortex size and group size across primates suggests that humans live in groups (or, rather, social networks) of approximately 150 individuals (Dunbar 1993). While there is some evidence to support this claim in the ethnographic literature (Dunbar 1993), no concerted attempt has so far been made to test this prediction in contemporary society.

We proposed that Christmas represents the one time of year when individuals in Western cultures make a concerted effort to make contact with their entire social network, or at least with those individuals whose rela- 
tionships they value and consider important. In addition to personal faceto-face contact, the sending of Christmas cards allows us to reach those individuals for whom physical distance or time prevent us from meeting in person. Estimated on this basis, the mean network size for the individuals in this sample was 153.5 individuals, with a slightly lower figure of 124.9 if only those individuals that respondents actually intended to contact are considered (i.e., excluding certain other members of the recipient's household). Both of these values fall well within the confidence limits (100 to 231) for human group sizes predicted on the basis of the relationship between neocortex size and group size across primates (Dunbar 1993), the observed maximum network size being remarkably close to the value of 147.8 ( \pm 45.8 ) predicted for humans. Furthermore, the network size for those individuals actively contacted is close to the value of 134 obtained by Killworth et al. (1984) in their attempt to estimate the number of individuals that subjects felt they could ask a favor of in small world experiments. This could be interpreted as suggesting that social networks contain a (small) number of individuals who might be considered peripheral to the core network, but who are nonetheless included because they form part of the immediate household or family of a core network member. Such individuals might not be considered appropriate people to seek favors from and might not themselves be granted support so readily. However, the extent to which these results can be generalized to all individuals cannot really be addressed.

Previous studies have shown that there can be considerable variation in social network size between individuals, with factors such as age (Dickens and Perlman 1981), marital status (Rands 1988), gender (Dunbar and Spoors 1995), physical attractiveness (Reis et al. 1982), personality (Wilson 1995), and levels of education, occupation, and income (Belle 1982) being major influences on network size and structure. These factors almost certainly account for some of the variation observed in the present study. Although our methodology precludes us from commenting on gender differences in network size, and we did not request details of respondents' social or personal circumstances, we are able to comment on the effects of age. In our study, significant changes were observed in network structure with age, most notably with respect to the demographic composition. From about 30 years of age onward, couples and families make up a higher a proportion of the total network, and this trend persists until late in life. One likely explanation for this is that changes in network composition are influenced by the presence of dependent children. However, despite the changes in general network composition, there is little change in the proportion of kin in the network, suggesting that these relationships remain relatively constant throughout life.

Kinship is known to play an important role in human social relationships 
(Dunbar and Spoors 1995; Hughes 1988; Keesing 1975), even though kin do not necessarily account for a large proportion of the network. In Killworth et al.'s (1984) study, less than $10 \%$ of the total network was identified as kin, with the vast majority $(86 \%)$ considered friends. Dunbar and Spoors (1995) reported a figure of $37.5 \%$ for the proportion of $\mathrm{kin}$, although this study focused on sympathy group sizes and so the figure is likely to be an overestimate of kin in the total network because kin are more likely to appear in the more proximal segments of the network. The proportion of kin in the total network reported here (approximately $21 \%$ ) lies comfortably between these two values. The fact that only $4 \%$ of the network was identified as non-genetic (affinal) relatives could be explained by one of two possibilities. First, it may be that not all affinal relatives were so identified on the questionnaire, but may instead have been listed as biological relatives. This suggestion is given credence by the fact that the incidence of single individuals and divorcees in our sample is unlikely to have been such as to produce such a significant level of bias. The second possibility is that affinal kin receive much less attention than biological kin. Either way, the results of this study suggest that, even though most of an individual's social network is composed of unrelated individuals, kin (and principally biological kin) are included with disproportionately high frequencies given their actual representation within both the national and the local populations.

Frequency of contact with members of the social network is determined by two general groups of factors: extrinsic factors (that impact on the likelihood of face-to-face meetings) and intrinsic factors (that determine the frequency with which individuals are intentionally contacted). Distance and whether the individual is a work colleague are the primary extrinsic factors influencing frequency of contact, although the former is supplemented by whether or not the individual concerned lives overseas. Note, however, that the sign for this factor is reversed in the multivariate analysis: overseas individuals are contacted more frequently than would be expected on the basis of distance, suggesting that special efforts may be made to keep contact with those core network members that live so far away that direct personal contact is precluded. This suggestion is given some support by the fact that, in such cases, a letter is often also included with the Christmas card (i.e., a greater effort is made to keep recipients abreast of news about the sender's family).

As far as intrinsic factors are concerned, emotional closeness and the coefficient of relatedness, for both genetic and affinal relatives, are the key parameters influencing frequency of contact. In both cases, individuals are contacted more frequently as closeness increases, reflecting the importance of these relationships. (Note that, although we can expect these vari- 
ables to be correlated with each other, the regression equation given in Table 2 reports their independent effects.) With regard to relatedness, however, extrinsic factors could also be involved, since family gatherings could result in a higher frequency of contact that is independent of direct personal contact between individuals. Nevertheless, kin networks are also highly interconnected and frequency of contact might be "policed," ensuring that high rates of interchange are maintained. Hames (1979), for example, found that Ye'kwana villagers of Venezuela interact more often with close relatives.

Previous studies have suggested that social networks may be hierarchically differentiated, with larger numbers of progressively less intense relationships maintained at higher levels. Dunbar (1998) suggested that clusterings of relationships tended to occur at 5 (support cliques), 12-15 (sympathy groups), and 35 (bands) individuals, with further higher-level groupings at 500 and 1500-2000 (equating in the ethnographic literature to mega-bands and tribes, respectively). Support cliques (defined as all those individuals from whom one would seek advice, support, or help in times of severe emotional or financial distress) averaged 4.72 ( \pm 2.95 ) individuals in one UK sample (Dunbar and Spoor 1995) and $3.01( \pm 1.77)$ in a US sample (Marsden 1987), while an estimate of women's "hair care" networks among the !Kung San yielded a mean of 3.8 (Sugawara 1984). The value of 7 suggested by Figure 5 lies within the upper limits for the margin of error for these estimates. Published sympathy group sizes typically lie within the range of 10-15 individuals (mean of 10.9 \pm 6.8 : Buys and Larson 1979; mean of 11.6 \pm 5.64: Dunbar and Spoor 1995), although values as low as 7 (Hays and Oxley 1986) and as high as 15-20 individuals (McCannell 1988; Rands 1988) have been reported. Much of this variation can probably be explained by methodological differences between the studies: Buys and Larson (1979), for example, considered those individuals whose death would be personally devastating, whereas other studies have tended to use frequencies of contact over various time periods. The value of 21 suggested by Figure 3 lies at the upper limit of these estimates. However, two points are worth noting. First, frequency of contact displays a considerable degree of stochastic variation and such methods are also prone to self-reporting errors (Milardo 1988). Second, the value obtained in this study may be an overestimate because all household members were ascribed the same contact frequency but almost certainly do not share the same level of intimacy with the respondent. A figure in the region of 12-15 may thus not be unrealistic. Finally, in Dunbar's (1993) analysis of the group sizes characteristic of modern hunter-gatherer societies, a level of social organization of 30 to 50 individuals (mean $=37.7 \pm 16.8$ ) was observed; these groupings were often described as bands or overnight camps 
in the ethnographic literature. The grouping level at 35 individuals observed in the present study is sufficiently close to this value to suggest that its origins in hunter-gatherer societies may not be entirely ecological (as has previously been assumed). We attempt no explanations for the apparent grouping levels at 70 and 100 individuals that are tentatively suggested by Figure 5 . It is possible that these may in part be simple artifacts of our methodology, which required that all individuals must be contacted at least once a year if they were to be included in the study.

If we compare the four main grouping levels tentatively identified in Figure $5(7,21,35$, and 153.5$)$ with the mean values obtained for the various groupings identified in the literature (means of $3.8 \pm 2.29,11.3 \pm 6.19$, $37.7 \pm 16.8$, and 147.8 \pm 45.8 ), it is clear that the values observed in Figure 5 are better estimates of their nominally corresponding values from the literature than of any other group type (Table 4). In each case, the value from Figure 5 is significantly different (as reflected in the number of standard deviations that separate the two values) from all other values except the one to which it nominally corresponds (or, in some cases, the adjacent value). The only exceptions are the values of 7 and 21 , which do not differ significantly from the values of the nominal grouping or the next higher one. However, this is principally a consequence of the fact that sympathy groups have a relatively larger standard deviation than do either support cliques or bands. This obscures the fact that the value of 21 , for example, actually lies closer to the mean value for sympathy groups than it does to that for bands. Taken as a whole, Table 4 suggests that the deviations are

Table 4. Probability of the Four Grouping Levels Identified in Figure 5 Being an Estimate of the Four Types of Grouping Hitherto Identified in the Literature. In each case, the probability of identity is derived from the standard normal deviate separating the observed (row) and putative (column) value, given the variance in the latter. Values in bold indicate value is not significantly different from column value.

\begin{tabular}{lcccc}
\hline & \multicolumn{4}{c}{ Estimated Sizes of Grouping Types Identified in Literature } \\
\cline { 2 - 5 } This Study & $3.8 \pm 2.29$ & $11.3 \pm 6.19$ & $37.7 \pm 16.8$ & $147.8 \pm 45.8$ \\
\hline 7 & $z=1.4$ & $z=0.7$ & $z=1.8$ & $z=3.1$ \\
& $(p=0.090)$ & $(p=0.244)$ & $(p=0.034)$ & $(p=0.001)$ \\
21 & $z=7.5$ & $z=1.6$ & $z=1.0$ & $z=2.8$ \\
& $(p \ll 0.001)$ & $(p=0.058)$ & $(p=0.162)$ & $(p=0.003)$ \\
35 & $z=13.6$ & $z=3.8$ & $z=0.2$ & $z=2.5$ \\
& $(p \cdot \ll 0.001)$ & $(p<0.001)$ & $(p=0.436)$ & $(p=0.007)$ \\
153.5 & $z=65.4$ & $z=23.0$ & $z=6.9$ & $z=0.1$ \\
& $(p \ll 0.001)$ & $(p \ll 0.001)$ & $(p<0.001)$ & $(p=0.450)$ \\
\hline
\end{tabular}


least significant along the main diagonal, suggesting that there is an association between the grouping levels identified within this one sample and those identified in previous studies that focused on more specific types of relationship.

Note that these grouping levels are strictly cognitively defined: in effect, they are cognitive constraints on the number of individuals that can be maintained at a given intensity of relationship (presumably involving familiarity, trust, etc). The social characteristics attributed to these groupings or the way they are used within the social system and the labels attached to them are wholly open to negotiation: each society may make quite different use of these groupings. The only constraint is that if the social function requires or depends on a particular intensity of relationship, then that function may be restricted to a particular size of group. While cultural differences will exist in network structure (Kim and McKenry 1998), and networks within cultures may change through time (Ruan et al. 1997), the general grouping levels defined by cognitive constraints should remain consistent.

In summary, it seems that Christmas card networks provide useful insights into human social networks and support the idea that they are utilized to make (at least annual) contact with all those individuals whose relationships are considered important. Total network sizes estimated from Christmas card lists are remarkably close to the value of 150 predicted for human social group size based on the relationship between group size and brain size across primates. Furthermore, the hierarchical structure of human social groups hinted at by other studies seems to have some basis in reality, at least insofar as it is observed in the Christmas card networks of this UK sample. Thus, even in contemporary western societies, where individuals are operating egocentric networks within a virtually infinite array of social possibilities, social network size and differentiation reflect the sociocentric networks observed in traditional societies, suggesting that the cognitive constraints on network size may apply universally to all modern humans.

This project was funded by a grant from Hewlett Packard Research Laboratories (Bristol) and the Economic and Social Research Council (ESRC). The support of the ESRC is gratefully acknowledged. This work was part of the programme of the ESRC Research Centre for Economic Learning and Social Evolution (ELSE). We are grateful to all those who distributed and completed questionnaires, in particular J. M. Hill and R. Grainger.

Russell Hill (B.Sc., M.Phil, Ph.D.) is an Addison Wheeler Research Fellow at the University of Durham. His main research interests are in the evolution of 
mammalian social systems. Robin Dunbar (B.A., Ph.D.) is a professor of evolutionary psychology at the University of Liverpool. His research interests span mammalian behavioral ecology, including humans, cognitive mechanisms, and Darwinian psychology.

\section{REFERENCES}

Barrett, L., R. I. M. Dunbar, and J. E. Lycett 2002 Human Evolutionary Psychology. Basingstoke: Palgrave/Macmillan, and Princeton: Princeton University Press.

Barton, R. A., and R. I. M. Dunbar

1997 Evolution of the Social Brain. In Machiavellian Intelligence II, A. Whiten and R. Byrne, eds. Pp. 240-263. Cambridge: Cambridge University Press.

Belle, D. E.

1982 The Impact of Poverty on Social Networks and Supports. Marriage and Family Review 5:89-103.

Buys, C. J., and K. L. Larson

1979 Human Sympathy Groups. Psychology Reports 45:547-553.

Dickens, W. J., and D. Perlman

1981 Friendship over the Life Cycle. In Personal Relationships 2: Developing Personal Relationships, S. Duck, and R. Gilmour, eds. Pp. 91-122. London: Academic Press.

Dunbar, R. I. M.

1991 Functional Significance of Social Grooming in Primates. Folia Primatologica $57: 121-131$.

1992 Neocortex Size as a Constraint on Group Size in Primates. Journal of Human Evolution 22:469-493.

1993 Coevolution of Neocortical Size, Group Size and Language in Humans. Behavioural and Brain Sciences 16:681-735.

1998 The Social Brain Hypothesis. Evolutionary Anthropology 6:178-190.

Dunbar, R. I. M., and J. Bever

1998 Neocortex Size Predicts Group Size in Some Insectivores. Ethology 104: 695-708.

Dunbar, R. I. M., and M. Spoors

1995 Social Networks, Support Cliques, and Kinship. Human Nature 6:273290.

Hames, R. D.

1979 Relatedness and Interaction among the Ye'kwana: A Preliminary Analysis. In Evolutionary Biology and Human Social Behavior, N. A. Chagnon and W. Irons, eds. Pp. 238-249. North Scituate: Duxbury Press.

Hays, R. B., and D. Oxley

1986 Social Network Development and Functioning during a Lifetime Transi-

tion. Journal of Personality and Social Psychology 50:305-313.

Hughes, A.

1988 Evolution and Human Kinship. Oxford: Oxford University Press. 
Johnson, E., H. R. Bernard, P. D. Killworth, G. A. Shelley, and C. McCarty 1995 A Social Network Approach to Corroborating the Number of AIDS/ HIV+ Victims in the U.S. Social Networks 17:169-187.

Keesing, R. M. 1975 Kin Groups and Social Structure. New York: Holt, Rinehart, Winston.

Killworth, P. D., H. R. Bernard, and C. McCarty 1984 Measuring Patterns of Acquaintanceship. Current Anthropology 25:391397.

Killworth, P. D., E. Johnson, H. R. Bernard, G. A. Shelley, and C. McCarty 1990 Estimating the Size of Personal Networks. Social Networks 12:289-312.

Killworth, P. D., C. McCarty, H. R. Bernard, G. A. Shelley, and E. C. Johnson 1998 Estimation of Seroprevalence, Rape and Homelessness in the United States Using a Social Network Approach. Evaluation Review 22:289-308.

Kim, H. K., and P. C. McKenry 1998 Social Networks and Support: A Ccomparison of African Americans, Asian Americans, Caucasians, and Hispanics. Journal of Comparative Family Studies 29:313-334.

Kudo, H., and R. I. M. Dunbar 2001 Neocortex Size and Social Network Size in Humans. Animal Behaviour 62:711-722.

McCannell, $\mathrm{K}$.

1988 Social Networks and the Transition to Motherhood. In Families and Social Networks, R. M. Milardo, ed. Pp. 83-106. Newbury Park: Sage.

McCarty, C., H. R. Bernard, P. D. Killworth, G. A. Shelley, and E. C. Johnson 1997 Eliciting Representative Samples of Personal Networks. Social Networks 19:303-323.

McCarty, C., P. D. Killworth, H. R. Bernard, E. C. Johnson, and G. A. Shelley 2001 Comparing Two Methods for Estimating Network Size. Human Organization 60:28-39.

Marino, L.

1996 What Dolphins Can Tell Us about Primate Evolution. Evolutionary Anthropology 5:81-86.

Marsden, P. V.

1987 Core Discussion Networks of Americans. American Sociological Review 52:122-131.

Milardo, R. M.

1988 Families and Social Networks: An Overview of Theory and Methodology.

In Families and Social Networks, R. M. Milardo, ed. Pp. 13-47. Newbury Park: Sage.

Milardo, R. M., ed.

1988 Families and Social Networks. Newbury Park: Sage.

Pool, I. S., and M. Kochen

1978 Contacts and Influence. Social Networks 1:5-51.

Rands, M.

1988 Changes in Social Networks Following Marital Separation and Divorce.

In Families and Social Networks, R. M. Milardo, ed. Pp. 127-146. Newbury Park: Sage. 
Reis, H., L. Wheeler, N. Spiegel, M. Kernis, J. Nezlek, and M. Perri 1982 Physical Attractiveness and Social Interaction II: Why Does Appearance Affect Social Experience? Journal of Personality and Social Psychology 43:979996.

Ruan, D., L. C. Freeman, X. Dai, Y. Pan, and W. Zhang 1997 On the Changing Structure of Social Networks in Urban China. Social Networks 19:75-89.

Sugawara, $\mathrm{K}$.

1984 Spatial Proximity and Bodily Contact among the Central Kalahari San. African Study Monograph (Supplement) 3:1-43.

Tschudin, A.

1997 Relative Neocortex Size and Its Correlates in Dolphins: Comparisons with Humans and Implications for Mental Evolution. Ph.D. Thesis, University of Natal. Wilson, $\mathrm{R}$.

1995 An Investigation into the Effects of Individual Differences upon the Size and Composition of Individuals Social Networks. B.Sc. Dissertation, University of Liverpool. 